\title{
PSICOLOGIA NAS URGÊNCIAS: UM RELATO DE EXPERIÊNCIA NO ATENDIMENTO JUNTO AO CORPO DE BOMBEIROS MILITAR
}

\author{
PSYCHOLOGY IN URGENCIES: AN EXPERIENCE REPORT IN THE ATTENDANCE
}

WITH THE MILITARY FIRE DEPARTMENT

\author{
Gisele Regina da Cunha ${ }^{1}$ \\ Michelle Marques Souza Peixer ${ }^{2}$ \\ Maria Isabel do Nascimento-André 3 \\ Recebido em: 09 abr. 2017 \\ Aceito em: 03 maio 2018
}

\begin{abstract}
RESUMO: O presente trabalho é um relato de experiência de um estágio em psicologia, desenvolvido em um batalhão do Corpo de Bombeiros Militar. Tal estágio ocorreu no período de um ano entre o segundo semestre de 2014 e primeiro semestre de 2015, tendo como principais objetivos o acompanhamento aos profissionais nos atendimentos de urgência e emergência através da ambulância; orientação aos profissionais quanto a aspectos da atuação do psicólogo e fenômenos psicológicos; escuta qualificada aos profissionais; atendimento psicológico a vítimas e familiares. Neste período observamos o quão ampla pode ser a atuação da psicologia no campo das urgências, visto que sua contribuição abarca desde a sensibilização no atendimento às vítimas, quanto na orientação e intervenções diretas com os profissionais. Ao final do estágio percebemos a melhor compreensão dos profissionais quanto a atuação da psicologia, bem como, o aumento na humanização no atendimento às vítimas, trazendo benefícios tanto aos profissionais/instituição, vítimas, quanto às estagiárias.
\end{abstract}

Palavras-chave: Corpo de Bombeiros. Psicologia nas Urgências. Humanização.

ABSTRACT: The present article is an experience report of an internship in Psychology, developed in a Military Fire Department Battalion. This internship lasted for a year, between the second semester of 2014 and the first semester of 2015, having as main goals to accompany the professionals in the urgency and emergency care through the ambulance; orientation to the professionals about aspects of the Psychologist intervention and Psychological phenomena; qualified listening of the professionals; Psychological care to victims and their families. During this period, we observed how broad Psychological intervention can be in the field of urgencies, since its contribution embraces from sensibilization in the care for victims, to orientation and direct interventions with the professionals. At the end of the internship, we noticed a better comprehension of the professionals concerning the Psychology intervention, as well, the increase in the humanization in the victims' care, bringing benefits both for the professionals/institution, victims, and for the interns.

Keywords: Fire Department. Psychology in Urgencies. Humanization.

\footnotetext{
${ }^{1}$ Graduação em Psicologia pela Universidade do Vale do Itajaí - UNIVALI, Formação em Tanatologia pela Rede Nacional de Tanatologia - RNT. E-mail: giselereginac@gmail.com.

${ }^{2}$ Graduação em Psicologia pela Universidade do Vale do Itajaí - UNIVALI, Formação em Tanatologia pela Rede Nacional de Tanatologia - RNT. E-mail: michellepeixer@hotmail.com.

${ }^{3}$ Doutorado pela Universidad de Sevilla (Espanha). E-mail: minandre@gmail.com.
} 


\section{INTRODUÇÃO}

No ano de 2003 foi publicada a portaria 1863/2003 que institui a Política Nacional de Atenção às Urgências. Esta portaria visa garantir a universalidade, a equidade e a integralidade no atendimento e considera também que a atenção às "Urgências" deve fluir em todos os níveis do SUS (Sistema Único de Saúde). O documento prevê ainda o desenvolvimento de estratégias promocionais de qualidade de vida e saúde, capazes de prevenir agravos e proteger a vida (BRASIL, 2003). Neste sentido, o trabalho do psicólogo junto ao atendimento de "Urgência" visa abranger a fluidez e integralidade junto à população, conforme preconiza tal portaria, bem como, dar subsídio à equipe que trabalha diretamente neste tipo de atendimento.

Assim como a universalidade e a equidade, a integralidade no atendimento é um dos princípios básicos do SUS, que envolve os saberes de profissionais, de usuários e da comunidade na construção de um cuidado efetivo à saúde (KALICHMAN e AYRES, 2016). Corroborando tal princípio, Viegas e Penna (2013) destacam que a integralidade se refere a uma assistência ampliada, considerando o ser humano dotado de sentimentos, desejos, aflições e racionalidades. Sendo ainda, construída cotidianamente visando às transformações sociais e de autonomia do sujeito.

Diante disso, os autores acrescentam que dentre estes três princípios, a integralidade é o mais desafiador e difícil de garantir, pois demanda uma mudança na perspectiva profissional, visto que ações curativas ainda estão dissociadas da prevenção e promoção de saúde (VIEGAS e PENNA, 2013; KALICHMAN e AYRES, 2016).

Configura, assim, elemento fundamental para que a universalidade e a equidade da atenção à saúde, princípios consubstanciais ao de integralidade, se realizem de modo pleno, permitindo ao SUS perseguir os objetivos de que se investiu na Constituinte de 1988 (KALICHMAN e AYRES, 2016, p. 2).

Tendo em vista que uma das "portas de entrada" dos atendimentos de urgência se daria por intermédio dos atendimentos realizados pelos bombeiros, faz-se necessário compreender a dinâmica envolvida em tal atendimento. Este ocorre por meio da articulação entre Central de Operações (COBOM) e serviço de Auto Socorro de Urgência (ASU) articulação esta responsável pelo primeiro atendimento à vítima, desde o contato através da central de operações até a intervenção das guarnições junto ao ASU e encaminhamento a outras esferas de atendimento do SUS. Neste contexto, a agilidade no atendimento se faz necessária, sendo, muitas vezes, deixado de lado o que é singular e subjetivo do paciente, dando-se preferência às "urgências orgânicas” (MOURA, 1996).

Desta forma, a psicologia pode contribuir com estes profissionais, no sentido de fomentar um olhar humanizado para as demandas psicológicas que se apresentam na rotina de atendimentos/socorros, bem como, dar suporte para os profissionais através de orientação sobre fenômenos psicológicos/emocionais, ou, em relação às suas próprias demandas pessoais e emocionais.

Nesta perspectiva, um dos principais objetivos do estágio nessa instituição foi a 
humanização do atendimento, visto que o artigo 2 da Portaria 1863/2003, em seu inciso 7, aponta que uma das formas de organizar este serviço deveria ser através da qualificação da assistência das equipes na atenção às urgências, "em acordo com os princípios da integralidade e humanização" (BRASIL, 2003).

Pensar a atuação do psicólogo nas instituições militares não seria tarefa fácil. $O$ espaço de atuação desse profissional nessas instituições é relativamente pequeno e ainda há um número reduzido de profissionais atuando na área (NATIVIDADE, 2009). Por se tratar de um estágio com ênfase em saúde e integralidade, há a necessidade de que a psicologia se faça presente em espaços como este, auxiliando no atendimento direto à população, bem como, na saúde desse trabalhador (Bombeiro) que desempenha função tão essencial e repleta de estressores.

\section{O TRABALHO DO BOMBEIRO MILITAR}

O Corpo de Bombeiros Militar de Santa Catarina (CBMSC) tem por missão "Prover e manter serviços profissionais e humanitários que garantam a proteção da vida, do patrimônio e do meio ambiente, visando proporcionar qualidade de vida à sociedade". Para o cumprimento desta missão as atividades desenvolvidas são subdivididas em: Prevenção a Sinistros (Atividades Técnicas), Atendimento Pré-Hospitalar (APH), Educação Pública, Busca e Resgate, Combate a Incêndio, Emergências com Produtos Perigosos e Operações Aéreas, Ajuda Humanitária (SANTA CATARINA, 2016).

As solicitações de atendimento ocorrem através da Central de Operações (COBOM), pelo telefone 193, onde a população tem o primeiro contato com a instituição. Esta, por sua vez, aciona os serviços de apoio, de acordo com o tipo de ocorrência, para a efetivação do atendimento. Tal articulação pode variar entre ambulância de Auto Socorro de Urgência (ASU), Auto Bomba-Tanque de Resgate (ABTR) e/ou viatura de Auto Resgate $(A R)$, tratando-se esta última de serviço de apoio para captura de animais ou em ocorrências que exijam um número maior de profissionais.

A disponibilidade e destreza nestas atividades exercidas pelos bombeiros possui o reconhecimento da sociedade, pois estão ligadas a diferentes frentes de salvamento. Nesta premissa o título profissional "bombeiro" produz uma representação heroica e de salvação, uma espécie de super-homem. Acredita-se então que a profissão bombeiro militar possa produzir uma dupla responsabilidade, onde além de cuidar de seu ofício ainda se esforce em manter essa imagem heroica (SOUZA, 2013). A satisfação de dever cumprido, quanto aos salvamentos impregnados deste imaginário heroico, concomitante com as características estressoras do cotidiano de trabalho, reforçam a autoimagem de superhomens. Souza (2013) também ressalta que esta autoimagem heroica pode ser uma estratégia defensiva da profissão, então necessária ao enfrentamento dos riscos, produzindo o que Costa, Ribeiro e André (2014) chamam de "couraça". Diante disso, esses profissionais desconsideram seus problemas cotidianos, tratando-os como irrelevantes, se 
comparados às "desgraças" presentes em sua rotina profissional. Esse fator gera alta vulnerabilidade nos profissionais, mesmo que esta, na maioria das vezes, não seja percebida (por eles).

A partir dessa perspectiva é possível dizer que assim como em outros campos de trabalho, a profissão do bombeiro militar também é fonte de prazer e sofrimento. Essa dinâmica, descrita por Dejours, Abdoucheli e Jayet (1994), acontece quando a saúde mental do trabalhador depende não tão somente da existência do sofrimento e do prazer, mas de um equilíbrio em identificar situações de sofrimento e transformá-las em prazer. Esse equilíbrio seria o resultado de uma regulação que requer a construção de estratégias defensivas especiais, elaboradas pelos próprios trabalhadores/bombeiros.

Neste sentido, ainda é escasso o treinamento contínuo referente a este aspecto, assim como praticamente inexistente o suporte psicológico a estes profissionais. Daí a importância de serem constantemente capacitados, não somente em atendimento préhospitalar, mas também no sentido de saberem lidar com suas frustrações e ansiedades frente às situações estressantes do seu trabalho.

Importante considerarmos que a atuação neste tipo de atendimento de urgência tem o agravante de que raramente sabem qual atendimento será prestado, bem como, as características e agentes que poderão interferir em tal atendimento, sendo que o inesperado é rotineiro no trabalho. Neste segmento, precisam estar não tão só em bom condicionamento físico, mas também com um bom condicionamento psíquico para saber lidar com situações estressantes. É necessário, portanto, estar pronto para uma tomada de decisão imediata, fator inerente desta profissão, porém, devem fazê-lo com qualidade e de forma mais humanizada para as vítimas e seus familiares (VEGIAN e MONTEIRO, 2011). Ressalta-se que o atendimento humanizado também oferece um ambiente mais tranquilo para o bombeiro, possibilitando uma possível diminuição no estresse que eles vivenciam no dia a dia, melhorando a sua efetiva intervenção.

\section{CONTRIBUIÇÕES DA PSICOLOGIA NOS ATENDIMENTOS DE URGÊNCIA}

Entre as diretrizes da Política Nacional de Atenção às Urgências, reformulada pela Portaria 1.600/GM, em julho de 2011, está a garantia da universalidade, equidade e integralidade no atendimento às urgências clínicas, cirúrgicas, gineco-obstétricas, psiquiátricas, pediátricas e às relacionadas a causas externas (traumatismos, violências e acidentes), humanização da atenção, garantindo efetivação de um modelo centrado no usuário e baseado nas suas necessidades de saúde, entre outras (BRASIL, 2011).

Nesta perspectiva, a intervenção da psicologia dentro do Corpo de Bombeiros Militar de Santa Catarina objetivaria ampliar as práticas de saúde e auxiliar no manejo da subjetividade das vítimas e dos próprios profissionais. Tal atuação corrobora o que traz a Política Nacional de Humanização, que define humanizar, por valorização dos sujeitos implicados no processo de produção de saúde (sejam usuários, trabalhadores ou gestores), 
através da oferta de atendimento de qualidade, articulação dos avanços tecnológicos com o acolhimento, melhoria dos ambientes de cuidado e das condições de trabalho dos profissionais, promoção da autonomia e o protagonismo dos sujeitos, a corresponsabilidade, estabelecimento de vínculos, construção de redes de apoio em saúde e cogestão (BRASIL, 2004).

Considerando que no contexto de urgências e emergências não são apenas demandas físicas que emergem, mas também psíquicas, o trabalho do psicólogo deve procurar minimizar a intensidade das reações advindas da situação inesperada a qual se encontra a vítima. Afinal sua rotina é subitamente atravessada pelo inusitado mal-estar ou um acidente, de ordem diversa, que além das consequências orgânicas pode provocar uma condição perturbadora, composta por uma gama de sentimentos (medos, fantasias, inseguranças, desamparo, tristezas, sensação de impotência, ansiedade, entre outros). Esta atenção ao sofrimento não tão somente físico proporciona os primeiros passos em direção a inovação no acolhimento e para a humanização nos serviços de Urgência e Emergência (ALMONDES, SALES, MEIRA, 2016; VIEIRA, 2010).

O psicólogo também colabora com a equipe, intermediando a relação equipe/paciente/família, na preparação do paciente, no que tange ao controle de sua ansiedade, assim como no repasse de informações adequadas sobre os elementos relacionados ao evento e procedimentos que serão realizados. Institui-se como porta-voz das necessidades, desejos, e intervém de forma que os desencontros da informação sejam minimizados. Possibilita um clima de confiança e segurança, facilitando que o próprio paciente e/ou a família verbalize seus medos suscitados pelas perspectivas do atendimento, dores, incômodos e demais sentimentos que possam surgir. A intervenção do psicólogo também auxilia na relação equipe/paciente à medida que sensibiliza a equipe para aspectos psicossociais que dificultam a comunicação com o paciente (ALMONDES, SALES, MEIRA, 2016; VIEIRA, 2010). Esta mediação pode possibilitar aos profissionais um olhar mais humanizado, entendendo que mesmo quando fisicamente não há alterações graves que demande risco de morte, pode sim haver sofrimento.

\section{MÉTODO}

Trata-se de atividades relativas ao estágio obrigatório de $9^{\circ}$ e $10^{\circ}$ períodos do Curso de Psicologia da Universidade do Vale do Itajaí. As atividades foram realizadas durante o segundo semestre de 2014, e primeiro semestre de 2015. O período das intervenções consistia em 10 (dez) horas semanais, que variavam de acordo com a disponibilidade das estagiárias e da instituição. Dentre as atividades realizadas constavam: acompanhamento aos profissionais nos atendimentos de urgência e emergência realizados pela equipe do Corpo de Bombeiros através do ASU; orientação aos profissionais quanto a aspectos da atuação do psicólogo, demandas do campo psi e sobre os fenômenos psicológicos; escuta qualificada aos profissionais; mediação entre bombeiros/vítimas/acompanhantes quando necessário. 
As intervenções desenvolvidas nos atendimentos de urgência consistiram em ofertar suporte psicológico e acolhimento à família, amigos ou pessoa próxima que estivesse no local, assim como, à própria vítima, caso a mesma estivesse em condições de responder a intervenção das estagiárias. Durante a ocorrência, além de técnicas de relaxamento que buscavam acalmar a vítima (quando necessário), era também realizada triagem, visando detectar possíveis danos psíquicos e emocionais, objetivando estender o acompanhamento dos casos mais graves e/ou que as estagiárias identificassem haver uma necessidade de cuidado pós-atendimento. Nestes casos, eram realizadas orientações às vítimas no sentido de buscarem acompanhamento psicológico gratuito em longo prazo e indicados os seguintes serviços: CAPS ad, CAPS II, Clínica de Psicologia da UNIVALI ou para Unidades Básicas de Saúde.

\section{RESULTADOS E DISCUSSÃO}

Durante o período de estágio diversas foram as intervenções realizadas no campo da psicologia. Tais intervenções se situavam tanto na escuta qualificada ofertada aos profissionais quanto no apoio às equipes nos atendimentos prestados, com acolhimento direto às vítimas ou através de elucidações sobre os aspectos psicológicos/emocionais envolvidos nas ocorrências.

As escutas e orientações faziam parte da rotina do estágio, tendo em vista que elas não aconteciam com agendamento, ocorrendo durante o período em que o estagiário encontrava-se presente e disponível. Um dos maiores dificultadores desse trabalho foi a resistência existente na instituição, tendo em vista a imagem de "heroísmo" construída sobre essa profissão. Desta forma, era necessário que não houvesse a presença de mais profissionais no local, pois se um colega visse outro em atitude de desabafo, este poderia virar motivo de piada.

Com relação ao serviço prestado durante as ocorrências, este era inicialmente realizado pelos bombeiros, através dos procedimentos padrões de checagem dos sinais vitais, bem como, dos agravos orgânicos provocados pela situação inesperada que demandara tal ocorrência. Neste sentido, além das demandas orgânicas também emergiam aspectos psicológicos/emocionais, os quais, muitas vezes eram as causas primárias dos sintomas físicos. As crises de ansiedade, por exemplo, podem produzir vários sintomas físicos, como taquicardia, sudorese, dor de cabeça, tontura, diarreia, falta de ar, boca seca, pele fria, palidez, indigestão, entre outros. Por estas manifestações físicas, muitas vezes o Corpo de Bombeiros Militar é acionado no atendimento de emergências (MORAES e SILVA, 2015).

Dentre as diversas ocorrências acompanhadas, relataremos algumas em que o atendimento psicológico se apresentara como foco principal de intervenção. Como podemos ver no CASO 1, onde os bombeiros foram chamados por uma Unidade de Saúde para atendimento de um adolescente que apresentava quadro de taquicardia e dificuldade 
de respiração (dispneia). Chegando ao local os bombeiros verificaram que os batimentos cardíacos do adolescente, que naquele momento já estava no oxigênio, estavam realmente alterados. Optou-se então por conduzi-lo à Unidade de Pronto Atendimento - UPA, para que permanecesse em observação. Durante o percurso, a estagiária interveio com 0 mesmo, buscando entender o que havia ocorrido e o que poderia ter desencadeado tal situação, tendo em vista que o mesmo não possuía histórico de problemas cardíacos. $\mathrm{A}$ partir disso, passou a questionar sobre o que ocorrera, bem como, sobre aspectos de sua vida emocional, afetiva, familiar. Enquanto o adolescente falava, a técnica de enfermagem que estava de plantão na ambulância (bombeira comunitária) observou que os batimentos cardíacos do mesmo começaram a estabilizar, assim como sua respiração. Desta forma, como já era tarde e não havia ninguém que os buscassem de volta, fora sugerido a sua liberação (do adolescente), tendo em vista que seus sinais vitais estavam normalizados. Foi orientado à sua mãe que caso os sintomas retornassem, poderia chamar novamente os bombeiros. Assim, esta assinou o termo de desistência da condução e foram deixados em local próximo a sua residência.

Através da intervenção da psicologia foi possível suscitar uma resposta física do adolescente com a diminuição dos batimentos cardíacos e a normalização da respiração. Segundo Stella e Pereira (2003) as crises não-epiléticas não possuem origem em alterações bioelétricas; sua origem está associada a processos psíquicos geralmente inconscientes e conduzem a manifestações sintomáticas dissociativas e conversivas, porém, não se pode negar o sofrimento do paciente. A ação fora eficaz e, em seus efeitos, evitara a condução da vítima e o dispêndio de recursos públicos para tal atendimento. Outro aspecto importante foi a visualização da equipe dos bombeiros para o trabalho da psicologia, sendo que, um dos bombeiros de plantão, chegou a relatar que se tivessem sempre um profissional de psicologia junto aos atendimentos, evitariam muitas conduções desnecessárias.

Outro exemplo a ser citado é o CASO 2, uma solicitação para mal-súbito, ocorrida em um estabelecimento público. Ao chegar no local, os bombeiros checaram os sinais vitais da vítima, que se encontravam estáveis. Durante esse procedimento realizaram uma conversa, a fim de investigar a origem dos sintomas (sudorese, palidez, calafrios e taquicardia). A vítima relatou ao bombeiro que tinha episódios de insônia, e realizou uma consulta médica, onde lhe foi dado o diagnóstico de algo que ela não sabia dizer ao certo "um negócio do pânico, acho que síndrome" (SIC), e receitado um medicamento ansiolítico, o que intensificou sua insônia. Ao perceber que o quadro físico era secundário a sintomas psicológicos/emocionais, o bombeiro fez orientações sobre um retorno ao médico para rever a medicação, e apresentou a estagiária de psicologia, possibilitando uma intervenção. Todos saíram da sala, ficando somente a estagiária e a vítima. Neste momento houve uma conversa, onde a vítima, entre momentos de choro, relatou que estava passando por um período de sobrecarga profissional, e por fazer auto cobranças, em relação a seu desempenho profissional, não conseguiu lidar com um apontamento feito pelo chefe em relação a um pequeno erro que cometeu. Referiu também muitas expectativas referentes a uma viagem familiar que aconteceria em poucos dias (medo de não conseguir preparar as 
coisas, como as malas e documentações, e deixar seu trabalho acumulando na sua ausência). Destarte, a intervenção da estagiária ocorreu no sentido de possibilitar que a vítima externalizasse seus sentimentos, visando acalma-la e possibilitando a remissão dos sintomas físicos. Desta forma, não foi necessário o deslocamento da vítima para um pronto atendimento. Realizou-se também elucidações sobre ansiedade e transtorno de pânico, e orientação sobre a possibilidade de acompanhamento terapêutico, independente do uso ou não de medicamentos.

É necessário que haja compreensão para perceber que estes sintomas são, na verdade, uma sensação de medo e apreensão, caracterizada por nervosismo, tensão e irritabilidade. A esta sensação damos o nome de ansiedade. Essa manifestação pode passar a ser patológica quando a reação é desproporcional à situação, dificultando o alcance de equilíbrio. Neste sentido o acompanhamento psicológico visa possibilitar estratégias de enfrentamento para lidar com tal fenômeno, entendendo a ansiedade como uma reação normal, adaptativa e positiva do organismo em reposta contra ameaças ou perigos que impulsiona o aumento de nossos esforços e desempenho (MORAES e SILVA, 2015).

Além das intervenções com as vítimas, outra ação muito comum, durante o estágio, foi o atendimento a familiares. No CASO 3 fica expressa a importância de profissional (psicólogo) que possa realizar esse suporte no momento do ocorrido. Tratou-se de um infarto em via pública. Ao chegarmos no local, a esposa encontrava-se abraçada à vítima. Inicialmente houve certa dificuldade em retira-la de perto do marido para o atendimento dos bombeiros. Neste sentido a estagiária de psicologia foi requisitada a intervir para tentar afastar a familiar, dando-Ihe suporte, tendo em vista seu estado emocional. Neste caso, o atendimento da psicologia foi fundamental. Como não foi possível socorrer a vítima, uma vez que esta já estava em óbito, foi solicitado a estagiária que repassasse a informação para os familiares. A partir desse momento, o movimento foi em levar a esposa para o interior da ambulância, a fim de preserva-la da desnecessária exposição - devido à presença de muitos populares que se encontravam no local. Nesta situação o atendimento consistiu em permitir que a mesma extravasasse seus sentimentos. Assim permaneceram, em silêncio, respeitando aquele momento e principalmente permitindo que externalizasse suas emoções através do choro. Após certo tempo, a mesma começou a se acalmar, sendo orientada sobre os procedimentos a serem tomados a partir dali. Segundo a perspectiva sistêmica, a perda é um processo transicional que envolve a pessoa morta e os sobreviventes em um ciclo de vida comum. Alcançar o equilíbrio neste processo é uma das tarefas mais difíceis que uma família pode enfrentar (WALSH e MCGOLDRICK, 1998).

O CASO 4 refere-se a ocorrência de uma vítima por arma branca. Ao chegar no local se constatou que a vítima estava deitada no chão da cozinha, com múltiplos cortes por todo o corpo, alguns superficiais e outros nem tanto, estando o chão muito sujo de sangue. A vítima não respondia aos questionamentos, apresentando-se catatônica, com olhar vago, como se estivesse inconsciente. Familiares que estavam no local relataram que a vítima foi quem realizou as lesões, e que a mesma já tentara suicídio outra vez, tomando 
vários medicamentos hipertensivos (todos juntos). A vítima foi colocada na maca, já que não respondia às solicitações, e a princípio seria encaminhada para a emergência do hospital. Os familiares não puderam acompanhar a vítima na ambulância, pois precisavam preencher o boletim de ocorrência junto a Polícia Militar, que também estava no local, devido à gravidade da situação.

Dentro da Ambulância a estagiária realizou algumas tentativas de contato com a vítima, sem sucesso. Porém, aos poucos, com perguntas como: "Posso tirar o cabelo que está sobre seu rosto? Você está com frio? Quer que eu abaixe sua blusa?" (para verificar a gravidade dos cortes a blusa foi levantada), a paciente começou a sinalizar respostas, balançando a cabeça, referindo que sim ou que não, iniciando um vínculo. Ao verificar que a paciente começou uma comunicação, o bombeiro que estava sentado do lado da estagiária passou para parte da frente da ambulância, permitindo que vítima e estagiária pudessem conversar de forma mais privada. Pouco a pouco a vítima passou a verbalizar suas angústias, explicando que realmente foi uma tentativa de suicídio, onde se lesionara com a faca de serra, que encontrou em cima da mesa. E (emendara) que pretenderia tentar outra vez. Falou sobre falta de vontade de realizar tarefas e de viver; e relatou que gostaria de voltar a ser a pessoa ativa que era antes destes sentimentos. A estagiária orientou sobre a necessidade de tratamento e perguntou se poderia entrar em contato posterior para novas orientações. Porém, a vítima não conseguiu lembrar seu telefone, pois se apresentava confusa. Desta forma foi acordado que a estagiária entraria em contato com a mesma, através da Unidade Básica de Saúde. O acolhimento realizado pela estagiária, cuja intervenção se baseava no diálogo, visava a escuta e valorização da queixa da vítima, identificando as suas necessidades. $O$ acolhimento permitira o relacionamento e criação de vínculo com a vítima, favorecendo um encontro onde esta fosse percebida não apenas por suas debilitações físicas, devido a ocorrência, mas sim como uma pessoa com necessidades e desejos (VIEIRA, 2010).

Ao perceberem que a paciente já se encontrava mais lúcida e o caso não implicasse em risco de morte iminente, o encaminhamento foi feito para a Unidade de Pronto Atendimento - UPA, onde a paciente já respondia às orientações dos bombeiros e realizou seu deslocamento deambulando. Um dos bombeiros presente na ocorrência relatou que naquele momento viu a efetividade do trabalho da psicologia, onde a vítima falou sobre seus sentimentos e conseguiu sair do estado de inércia ao qual se encontrava e cooperar com seu atendimento.

\section{CONCLUSÃO}

O presente relato descreveu algumas das atividades realizadas no estágio do curso de psicologia, o qual fora, pelo período de um ano, realizado em um Batalhão do Bombeiro Militar. Tal atividade possibilitou ampliar as competências profissionais necessárias para 0 exercício da profissão, pois atuar nas situações de emergência permitiu a aquisição de respostas ágeis a acontecimentos inesperados, que então devem ser executadas de forma 
calma e clara. O campo envolveu diferentes possibilidades de intervenção, que variaram entre escuta e aconselhamento aos bombeiros e o atendimento às vítimas de urgência e/ou seus parentes.

Pode-se observar que em muitas ocorrências das quais as estagiárias participaram, apesar de a queixa latente ser proveniente de sintomas físicos, muitas dessas demandas acabavam se apresentando com um cunho emocional. Os casos que mais demandavam intervenções do campo da psicologia, durante os atendimentos, foram estresse frente à situação da ocorrência, crises de ansiedade, tentativas de suicídios, entre outros. Ficou claro que ao lidar com tais situações é imprescindível que o profissional da psicologia proporcione um atendimento humanizado, com o intuito de beneficiar a vítima frente a situação estressora. Desta forma o atendimento se transforma em uma via de mão dupla, pois além de beneficiar o paciente e auxiliar a equipe nos atendimentos, também possibilita o crescimento profissional das estagiárias.

É possível perceber uma evolução nas possibilidades de intervenção neste campo, se considerarmos algumas dificuldades apresentadas por Ribeiro, Costa e NascimentoAndré (2014) no seu relato de experiência de estágio em psicologia no mesmo campo de atuação, que eram pautadas principalmente na falta de conhecimento dos bombeiros quanto ao fazeres do psicólogo. Neste sentido também percebemos esta evolução em nossas próprias intervenções, como nos CASOS 1 e 4 apresentados, onde as estagiárias buscaram as intervenções; enquanto nos CASOS 2 e 3, já familiarizados com o trabalho da psicologia, os próprios bombeiros buscam a ajuda das estagiárias. Percebe-se que esta ampliação do olhar dos profissionais/bombeiros para com o trabalho das estagiárias aconteceu pela continuidade dos estágios neste contexto e através de atendimentos pontuais e resolutivos feitos pela psicologia.

O estágio não buscou tornar os bombeiros dependentes da ajuda de um profissional da psicologia, a cada novo atendimento; porquanto se soubesse que tal formato fosse inviável. A intenção antes seria demonstrar que além da rápida resposta quanto às emergências orgânicas seria também preciso não perder de vista a escuta, o acolhimento, a subjetividade do outro que sofre. Pois a humanização é uma mudança que deve ocorrer não apenas nas estruturas e nas formas de trabalhar, mas também nas pessoas.

Ressalta-se novamente a importância do trabalho da psicologia dentro deste contexto no treinamento contínuo dos profissionais, assim como no suporte psicológico aos mesmos. Pois embora o estágio possuísse um enfoque em saúde e integralidade, durante um ano de intervenção não deixamos de considerar os componentes institucionais que permeiam o viés de organizações e comunidades. Foi possível observar algumas possiblidades de trabalho a serem desenvolvidas no campo.

Como sugestões para futuros projetos, podemos propor intervenções no campo do estresse ocupacional com foco no atendimento ao trabalhador, como o treino de habilidades de relacionamento interpessoal, não só para praças como também oficiais; a minimização dos impactos das relações hierárquicas, através da sensibilização dos oficiais e um trabalho com os profissionais em final de carreia, na preparação para a aposentadoria. Tais 
propostas devem objetivar a minimização de situações que gerem sofrimento e desconforto laboral.

Outra ação que pode ser desenvolvida é a realização de rodas de conversa sobre as demandas psicológicas que muitas vezes são desconhecidas pelos profissionais da corporação, como crises conversivas, transtornos de humor e personalidade, etilismo e subjetividade, bem como, possibilitar aos mesmos que expressem suas próprias demandas e angústias relacionadas a práxis profissional.

Pensando nas situações externas à corporação, sugerimos divulgação junto a população sobre o serviço realizado pelos bombeiros e a diferenciação de outros órgãos públicos como SAMU, FAMAI, Polícia Militar, entre outros. Tal desconhecimento acaba aumentando o estresse e a demanda de trabalho, dificultando assim a realização do mesmo. Para isso, pode-se levantar como indicadores de tal necessidade, o número de ligações junto ao COBOM que se referem a trotes ou a serviços que não são demanda para os bombeiros. Essa divulgação deve fazer com que a sociedade conheça em quais casos devem solicitar atendimentos a cada órgão, otimizando assim o serviço prestado, uma vez que o congestionamento de solicitações de atendimento ao Corpo de Bombeiros é devido a essa falta de conhecimento.

\section{REFERÊNCIAS}

ALMONDES, Katie Moraes; SALES, Eleni de Araújo; MEIRA, Maísa de Oliveira. Serviço de Psicologia no SAMU: Campo de Atuação em Desenvolvimento. Psicologia: Ciência e Profissão, v. 36, n. 2, p. 449-457, 2016. Disponível em:

<https://www.researchgate.net/publication/304339450>. Acesso em: 20 out. 2016.

BRASIL. Ministério Da Saúde. HumanizaSuS: Política Nacional de Humanização: a humanização como eixo norteador das práticas de atenção e gestão em todas as instâncias do SUS / Ministério da Saúde, Secretaria Executiva, Núcleo Técnico da Política Nacional de Humanização. Brasília: Ministério da Saúde, 2004. Disponível em:

<http://bvsms.saude.gov.br/bvs/publicacoes/humanizasus_2004.pdf>. Acesso em: 25 out. 2016.

. Ministério Da Saúde. Portaria GM N 1.600, de julho de 2011. Reformula a Política Nacional de Atenção às Urgências e institui a Rede de Atenção às Urgências no Sistema Único de Saúde (SUS). Diário Oficial da União, 2010, Seção 1, p. 80. Disponível em:

<http://bvsms.saude.gov.br/bvs/saudelegis/gm/2011/prt1600_07_07_2011.html>. Acesso em: 25 out 2016.

. Ministério Da Saúde. Portaria GM № 1863, de 29 de setembro de 2003. Institui a Política Nacional de Atenção às Urgências, a ser implantada em todas as unidades federadas, respeitadas as competências das três esferas de gestão. Diário Oficial da União, Brasília, 2003. Seção 1, p. 56. Disponível em:

<http://bvsms.saude.gov.br/bvs/saudelegis/gm/2003/prt1863_26_09_2003.html>. Acesso em: 25 out 2016 . 
COSTA, Etiene Pereira; RIBEIRO, Ana Cláudia Pereira; NASCIMENTO-ANDRÉ, Maria Isabel do. A Psicologia na Urgência e Emergência: Uma experiência no Corpo de Bombeiros. Revista Interdisciplinar de Estudos em Saúde, v. 3, n. 2, p. 68-78, 2014. Disponível em: <http://www.periodicosuniarp.com.br/ries/article/view/294/0>. Acesso em: 15 ago. 2016.

DEJOURS, Christophe; ABDOUCHELI, Elisabeth; JAYET, Christian. Psicodinâmica do trabalho: Contribuições da escola dejouriana à análise da relação prazer, sofrimento e trabalho. São Paulo: Atlas, 1994.

KALICHMAN, Artur Olhovetchi; AYRES, José Ricardo de Carvalho Mesquita. Integralidade e tecnologias de atenção à saúde: uma narrativa sobre contribuições conceituais à construção do princípio da integralidade no SUS. Rev. Cad. Saúde Pública, Rio de Janeiro, v. 32, n. 8, p. 1-13, 2016. Disponível em:

<http://www.scielo.br/pdf/csp/v32n8/1678-4464-csp-32-08-e00183415.pdf >. Acesso em: 22 out. 2016.

MORAES, Maria Camila Ferreira; SILVA, Niedja Pereira da. Saúde mental e as relações de trabalho: como ansiedade influencia o comportamento humano no ambiente de trabalho. Interfaces de Saberes, v. 14, n. 1. 2015. Disponível em: <https://interfacesdesaberes.fafica-pe.edu.br/index.php/import1/article/view/533/274>. Acesso em: 24 out. 2016.

MOURA, Marisa Decat de. Psicanálise e Hospital. Rio de Janeiro: Editora Revinter, 1996.

NATIVIDADE, Michelle Regina da. Vidas em risco: A identidade profissional dos Bombeiros Militares. Revista Psicologia e Sociedade, v. 21, n. 3, p. 411-420, 2009. Disponível em: <http://www.scielo.br/pdf/psoc/v21n3/a15v21n3>. Acesso em: 25 out. 2016.

SANTA CATARINA, Corpo de Bombeiros Militar. Disponível em: <https://portal.cbm.sc.gov.br/>. Acesso em: 24 out. 2016.

SOUZA, Kátia Maria Oliveira de. A análise da relação trabalho e saúde na atividade dos bombeiros militares do Rio de Janeiro. 2013. 152 f. Tese (Doutorado em Ciências na área de Saúde Pública) - Escola Nacional de Saúde Pública Sergio Arouca, Rio de Janeiro, 2013. Disponível em: <https://www.arca.fiocruz.br/handle/icict/14361>. Acesso em: 23 mar 2017.

STELLA, Florindo; PEREIRA, Mário Eduardo Costa. Semiologia e características clínicas das crises pseudo-epilépticas. Rev. Latinoamericana de Psicopatologia Fundamental. v.1, n 1, p.1-16, 2003. Disponível em: <http://pesquisa.bvs.br/brasil/resource/en/psi18858>. Acesso em: 15 mar. 2015.

VEGIAN, Camila Fernanda Lourençon; MONTEIRO, Maria Inês. Condições de vida e trabalho de profissionais de um Serviço de Atendimento Móvel de Urgência. Rev. LatinoAm. Enfermagem, v. 19, n. 4, p.1-7, 2011. Disponível em: <http://www.revistas.usp.br/rlae/article/view/4409>. Acesso em: 22 de ago. 2016.

VIEGAS, Selma Maria da Fonseca; PENNA, Cláudia Maria de Mattos. A construção da integralidade no trabalho cotidiano da equipe de saúde família. Esc Anna Nery, Belo 
Horizonte, v. 17, n. 1, p. 133-141, 2013. Disponível em:

<http://www.scielo.br/scielo.php?script=sci_arttext\&pid=S1414-81452013000100019>. Acesso em: 20 set. 2016.

VIEIRA, Michele Cruz. Atuação da Psicologia hospitalar na Medicina de Urgência e Emergência. Revista Brasileira de Clínica Médica, São Paulo, v. 8, n. 6, p. 513-519, 2010. Disponível em: <http://files.bvs.br/upload/S/1679-1010/2010/v8n6/a1602.pdf>. Acesso em: 22 ago. 2016.

WALSH, Froma; MCGOLDRICK, Monica. Morte na Família: sobrevivendo às perdas. Porto Alegre: Artmed,1998. 